\title{
COLORECTAL CARCINOMA;
}

\section{FREQUENCY IN SOUTHERN PUNJAB.}

\author{
DR. QAISER MAHMOOD, \\ DCP, FCPS (Medicine), \\ Assistant Professor of Medicine \\ Nishtar Hospital, Multan. \\ DR. NASREEN SIDDIQUE, \\ MCPS, MSc. (Community Health \& Nutrition), \\ FCPS (Community Medicine), \\ Nishtar Hospital, Multan.
}
DR. AHMED IJAZ MASOOD, FCPS (Radiotherapy), Assistant Professor of RAdiology
Nishtar Medical College, Multan.

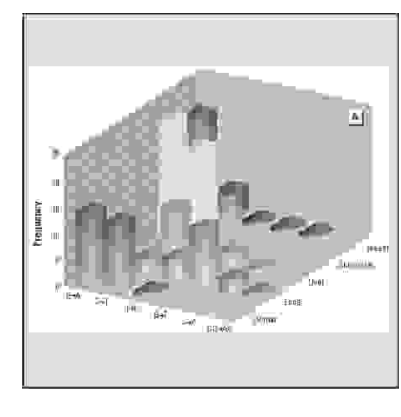

\begin{abstract}
Objective: To note the frequency of colorectal carcinoma in southern Punjab. Design: Retrospective observational study. Place and duration of study: Histopathology department Nishtar Hospital Multan from January 1993 to December 2003. Subject and Methods: Among 45114 surgical specimens received from January 1993 to December 2003, 526 were diagnosed as cases of colorectal carcinoma out of these 316 were male and 210 were female patients. Peak age for male was 51-60 years while for female it was 31-40 years. From all the received specimens, appropriate number of sections were passed, haematoxylin and eosin staining was done and light microscope was used for the diagnosis. Result: During ten year period total 526 cases were diagnosed as a case of colorectal carcinoma. Among them, rectal carcinoma was the most common with over all male predominance. Colorectal carcinoma was one to two decade earlier more common in female than in male. The commonest histological variant was adenocarcinoma with an increasing tendency towards left side of colon. Conclusion: Colorectal carcinoma is more common in males, earlier in females than males which needs further work up.
\end{abstract}

Key words: Colorectal, carcinoma, adenocarcinoma.

\section{INTRODUCTION}

Colorectal carcinoma is the most common gastrointestinal malignancy through out the western world. In U.K mortality associated with this carcinoma is approximately 200,000 per year, making it the second most common cause of death from malignant diseases ${ }^{1,2}$.

Colorectal carcinoma constitutes about $15 \%$ of newly diagnosed cancer, in most of the studies in USA and Europe $13 \%$ of all cancer death ${ }^{3}$. Peak incidence is between $60-70$ years .Fewer than $20 \%$ of cases occur before the age of 50 years ${ }^{4}$. Highest occurrence of this tumor is in USA, Canada, Australia and Newzeland while lower in Asia (Japan), South America, Africa ${ }^{4}$ and lowest in Ibadan (Nigeria) $)^{5}$. In Pakistan the incidence of colorectal carcinoma is increasing possibly as a result of 
industrialization or other factors ${ }^{6.7 .8 .9}$.

Various factors thought to be involved in the predisposition of colorectal carcinoma are alcohol consumption ${ }^{10,11,12}$, increased weight gain since the age of 25 years ${ }^{10}$ smoking (cigarettes, cigar and pipes), more for cigar and pipes than cigarettes smoking ${ }^{13,14,15}$ increased intake of dietary fat, protein ${ }^{3,4,16,17,18,19}$ and deficiency of micro-nutrients such as vitamin $A, C$ and $\mathrm{E}^{3,4}$, calcium $^{10}$, selenium ${ }^{16}$, beta- carotene ${ }^{3,10}$, socioeconomic status, type of housing, educational level ${ }^{20,21}$, age more than 40 years, associated diseases like ulcerative colitis, granulomatous colitis, past history (female breast cancer and genital tract cancer), family history, Familial polyposis, Gardner syndrome, Turcots syndrome, colorectal polyps, cancer family syndrome and generalized gastrointestinal juvenile polyposis have been blamed $^{16}$. Familial adenomatous polyposis is dominantly inherited cancer predisposition syndrome with incidence of $1: 17000$ and 1:5,00022.

Multan is situated in the lower central Punjab (Pakistan) and drains most of its surrounding population, climate is hot. Most of its population is rural and economy is agrobased, where there is indiscriminate exposure to pesticides. Nishtar Hospital, Multan is the main referral center. The frequency of colorectal carcinoma in
Southern Punjab is not known that's why this study was planned to know the frequency of colorectal carcinoma in this area.

\section{PURPOSE OF STUDY}

To note the frequency of colorectal carcinoma in southern Punjab.

\section{MATERIAL AND METHOD}

526 patients of colorectal carcinoma were carried out at pathology department Nishtar Hospital Multan from January 1993 to December 2003. Most of the received specimen were either resected segment of large intestine or few in the form of small endoscopic biopsies. Routinely an adequate number of sections are taken from the tumor, normal area and resected margins, routinely Haematoxylin and eosin stain are used. Histological diagnosis is made under the light microscope. Then cases were analyzed according to age ,sex, anatomical site of tumor and histological diagnosis.

\section{RESULTS}

Two cases were below the age of ten years and both were male while four cases were above the age of 80 years and all were females as shown in (Table I, II, \& III).

\begin{tabular}{|c|c|c|c|c|}
\hline \multicolumn{5}{|c|}{$\begin{array}{l}\text { Table- I Average Age Incidence of Colon Rectal Carcinoma } \\
\text { Between 1-90 years during 1983-December 2003. Total=526, Male=316, Female=210 }\end{array}$} \\
\hline Age & No. of Male & $\%$ Age & No. of Female & $\%$ Age \\
\hline $0-10$ & 02 & 0.4 & - & - \\
\hline $11-20$ & 10 & 1.80 & 10 & 1.90 \\
\hline $21-30$ & 28 & 05.3 & 24 & 4.56 \\
\hline $31-40$ & 48 & 9.1 & 56 & 10.64 \\
\hline $41-50$ & 74 & 14.0 & 48 & 9.12 \\
\hline $51-60$ & 82 & 15.6 & 38 & 7.22 \\
\hline $61-70$ & 60 & 11.4 & 20 & 3.80 \\
\hline $71-80$ & 12 & 02.3 & 10 & 1.90 \\
\hline $81-90$ & - & - & 04 & 0.76 \\
\hline Total & 316 & 59.9 & 210 & 39.9 \\
\hline
\end{tabular}


$178(33.84 \%)$ cases were below the age of 40 years, male were $88(16.73 \%)$ while the females were $90(17.11 \%)$. Between the age of $51-60$ years male were
$82(15.58 \%)$ and between the age of $41-50$ females were $48(9.12 \%)$ which is one to two decade earlier than the males.

\begin{tabular}{|c|c|c|c|c|}
\hline \multicolumn{7}{|c|}{ Table- II Distribution of Colon Rectal Carcinoma According to Age Group } \\
\hline Age & Male & Female & Total No. & \% Age \\
\hline $0-10$ & 02 & - & 02 & 0.4 \\
\hline $11-20$ & 10 & 10 & 20 & 3.80 \\
\hline $21-30$ & 28 & 24 & 52 & 9.88 \\
\hline $31-40$ & 48 & 56 & 104 & 19.78 \\
\hline $41-50$ & 74 & 48 & 122 & 23.19 \\
\hline $51-60$ & 82 & 38 & 120 & 22.81 \\
\hline $61-70$ & 60 & 20 & 80 & 15.20 \\
\hline $71-80$ & 12 & 10 & 22 & 4.18 \\
\hline $81-90$ & - & 04 & 04 & 0.76 \\
\hline Total & 316 & 210 & 526 & 100.0 \\
\hline
\end{tabular}

The most common carcinoma observed was rectal carcinoma, $238(45.24 \%)$ cases where male were $126(23.95 \%)$ and females were $112(21.70 \%)$, followed by carcinoma of caecum $110(20.91 \%)$ cases with again male predominance $61(11.59 \%)$ and carcinoma of recto sigmoid junction $50(9.50 \%)$ as shown in (Table IV).

Over all right sided colorectal carcinoma was observed in $159(30.22 \%)$ cases while $362(68.82 \%)$ cases were of left sided .as shown in (Table-IV) Which is $38.60 \%$ increase on left side .Predominant histological variant among the known sites was rectal carcinoma $238(45.24 \%)$ were male were $126(23.95 \%)$ and female were $112(21.70 \%)$ followed by caecum $110(20.91 \%)$ were male were $61(11.59 \%)$ and female were $49(9.31 \%)$ as shown in (Table IV \& V).

In changing site distribution of colorectal carcinoma the $\%$ age of right sided cancer was stable in males while increasing in females which is in comparison with our study as shown in table VI .

Adenocarcinoma which comprised of 485 (92.20\%) cases and leading among the Adenocarcinoma was mucinous adenocarcinoma 205(38.97\%) as shown in table-VII.

\begin{tabular}{|c|c|c|c|c|c|}
\hline \multicolumn{7}{|c|}{ Table - III Distribution of Colon Rectal Carcinoma According to Age and Sex } \\
\hline \multicolumn{3}{|c|}{ Male 316 } & \multicolumn{3}{c|}{ Female 210 } \\
\hline Age & No. & \% Age & Age Age & No. & 00 \\
\hline $0-10$ & 02 & 0.4 & $0-10$ & 10 & 1.90 \\
\hline $11-20$ & 10 & 1.80 & $11-20$ & $21-30$ & 24 \\
\hline
\end{tabular}




\begin{tabular}{|c|c|c|c|c|c|}
\hline $31-40$ & 48 & 9.1 & $31-40$ & 56 & 48 \\
\hline $41-50$ & 74 & 14.0 & $41-50$ & 38 & 9.12 \\
\hline $51-60$ & 82 & 15.6 & $51-60$ & 20 & 3.22 \\
\hline $61-70$ & 60 & 11.4 & $61-70$ & $71-80$ & 10 \\
\hline $71-80$ & 12 & 2.3 & $81-90$ & 04 & 0 \\
\hline $81-90$ & 00 & 00 & & 0.76 \\
\hline
\end{tabular}

\begin{tabular}{|c|c|c|c|c|c|c|c|}
\hline \multicolumn{8}{|c|}{ Table-IV Distribution Colon Rectal Carcinoma According to Site } \\
\hline \multicolumn{2}{|c|}{ Right Colon $=159(30.22 \%)$} & \multirow{2}{*}{$\begin{array}{c}\text { Total }=526 \\
\text { Male }\end{array}$} & \multicolumn{2}{|c|}{ Male $=90(56.60)$} & \multicolumn{3}{|c|}{ Female $=69(43.39)$} \\
\hline Site & No. of patients & & $\%$ age $\mathrm{T}$ & $\%$ age $M$ & Female & $\%$ Age T & $\%$ Age $\mathrm{F}$ \\
\hline Appendix & $6(1.14)$ & 4 & 0.76 & 1.26 & 2 & 0.38 & 0.95 \\
\hline Caecum & $110(20.19)$ & 61 & 11.59 & 19.30 & 49 & 9.31 & 23.33 \\
\hline Ascending colon & $27(5.13)$ & 15 & 2.85 & 4.74 & 12 & 2.28 & 5.71 \\
\hline Transverse Colon & $11(2.09)$ & 7 & 1.33 & 2.21 & 4 & 0.76 & 1.90 \\
\hline Hepatic flexure & $5(0.95)$ & 3 & 0.47 & 0.94 & 2 & 0.38 & 0.95 \\
\hline \multicolumn{8}{|c|}{ Left Colon $=362(68.82 \%)$} \\
\hline Site & No. of patients & Male & $\%$ age $\mathrm{T}$ & $\%$ age $M$ & Female & $\%$ Age T & $\%$ Age F \\
\hline Splenic flexure & $6(1.14)$ & 2 & 0.38 & 0.63 & 4 & 0.77 & 1.90 \\
\hline Descending colon & $23(4.37)$ & 12 & 2.28 & 3.79 & 11 & 2.13 & 5.23 \\
\hline Sigmoid colon & $24(4.56)$ & 14 & 2.66 & 4.43 & 10 & 1.93 & 4.76 \\
\hline Recto-sigmoid junction & $50(9.50)$ & 36 & 6.86 & 11.39 & 14 & 2.71 & 2.66 \\
\hline Rectum & $238(45.24)$ & 126 & 23.95 & 39.87 & 112 & 21.70 & 53.33 \\
\hline Anal canal & $16(3.04)$ & 10 & 1.90 & 3.16 & 6 & 1.16 & 2.85 \\
\hline Colon non specified & $5(0.95)$ & 3 & 0.57 & 0.94 & 2 & 0.38 & 0.95 \\
\hline
\end{tabular}

\begin{tabular}{|c|c|c|c|c|c|}
\hline \multicolumn{7}{|c|}{ Table-V Incidence of Colon Rectal Carcinoma in Different Parts of Colon } \\
\hline Site & No. of patients & Male & $\%$ Age from T. Male & Female & $\%$ Age from T. Female \\
\hline Appendix & $6(1.14 \%)$ & $4(0.76 \%)$ & 1.27 & $2(0.38 \%)$ & 0.95 \\
\hline Caecum & $110(20.91 \%)$ & $61(11.59 \%)$ & 19.30 & $49(9.31 \%)$ & 23.33 \\
\hline Ascending colon & $27(5.13 \%)$ & $15(2.85 \%)$ & 4.74 & $12(2.28 \%)$ & 5.71 \\
\hline Hepatic flexure & $5(0.95 \%)$ & $3(0.57 \%)$ & 0.94 & $2(0.38 \%)$ & 0.95 \\
\hline
\end{tabular}




\begin{tabular}{|c|c|c|c|c|c|}
\hline Transverse colon & $11(2.09 \%)$ & $7(1.33 \%)$ & 2.21 & $4(0.76 \%)$ & $4(0.76 \%)$ \\
\hline Splenic flexure & $6(1.14 \%)$ & $2(0.38 \%)$ & 0.63 & $11(2.13 \%)$ & 1.90 \\
\hline Descending colon & $23(4.37 \%)$ & $12(2.28 \%)$ & 3.79 & $10(1.93 \%)$ & 5.23 \\
\hline Sigmoid colon & $24(4.56 \%)$ & $14(2.66 \%)$ & 4.43 & $14(2.66 \%)$ & 4.76 \\
\hline Recto-sigmoid junction & $50(9.50 \%)$ & $36(6.84 \%)$ & 11.39 & $112(21.29 \%)$ & 6.66 \\
\hline Rectum & $238(45.24 \%)$ & $126(23.95 \%)$ & 39.87 & $6(1.16 \%)$ & 53.33 \\
\hline Anal canal & $16(3.04 \%)$ & $10(1.90 \%)$ & 3.16 & $2(0.38 \%)$ & 2.85 \\
\hline Colon non specified & $5(0.95 \%)$ & $3(0.57 \%)$ & 0.94 & 228 & 0.95 \\
\hline
\end{tabular}

\begin{tabular}{|c|c|c|}
\hline \multicolumn{2}{|c|}{ Table-VI Distribution Colon Rectal Carcinoma According to Histological Type } \\
\hline \multicolumn{3}{|c|}{ Total = 526 Male = 316 Female = 210 } \\
\hline Histological type & 485 & \% of patients \\
\hline A- Adenocarcinoma & 205 & 32.20 \\
\hline (i) Muscinous adenocarcinoma & 162 & 28.89 \\
\hline (ii) Moderately diff. & Adenocarcinoma \\
\hline (iii) Signet ring cell type & 112 & 21.29 \\
\hline (iv) Papillary adenocarcinoma & 09 & 1.7 \\
\hline (v) Adenosquamous carcinoma & 07 & 1.3 \\
\hline B- Non-Hodgkin lympha & 10 & 1.90 \\
\hline C- Carcinoid tumour & 07 & 1.3 \\
\hline D- Squamous cell carcinoma & 04 & 0.76 \\
\hline E- Lymphoma diffused type & 03 & 0.57 \\
\hline F- Unspecified & 07 & 1.3 \\
\hline
\end{tabular}

\begin{tabular}{|c|c|c|c|}
\hline \multicolumn{4}{|c|}{ Table-VII Distribution of Right and Left Colorectal Carcinoma } \\
\hline Site & No. of Cases & Male & Female \\
\hline Right colon & $159(30.22 \%)$ & $90(56.60 \%)$ & $69(43.39 \%)$ \\
\hline Left colon & $362(68.82 \%)$ & $203(56.07 \%)$ & $159(43.92 \%)$ \\
\hline
\end{tabular}




\section{DISCUSSION}

Colorectal cancer is the 2nd most common cause of death in the Western society ${ }^{23}$. Its incidence has increased among the elderly in the recent years ${ }^{24,25}$. Various genetic and environmental factors have been blamed as an etiology ${ }^{5}$ but none of them has been proved.

In this retrospective observational study a total of 526 cases were included, out of which $316(60 \%)$ were male and $210(40 \%)$ were female. Male to female ratio was 1.5:1 ranged between of 6-85 years. Two cases were below the age of ten years and both were male while four cases were above the age of 80 years and all were females. $178(33.84 \%)$ cases were below the age of 40 years, male were $88(16.73 \%)$ while the females were $90(17.11 \%)$. Between the age of $51-60$ years male were $82(15.58 \%)$ and between the age of $41-50$ females were $48(9.12 \%)$ which is one to two decade earlier than the male. Among the known sites the commonest site was rectal carcinoma $238(45.24 \%)$ were male were $126(23.95 \%)$ and female were $112(21.70 \%)$ followed by caecum $110(20.91 \%)$ male were $61(11.59 \%)$ and female were $49(9.31 \%)$. In our study major bulk of the neoplasm involved the rectum, caecum and recto sigmoid junction. This observation is nearly in accordance with as reported in other studies ${ }^{26,27,28,29}$. Right colon involvement was $159(30.22 \%$ ) while left colon $362(68.82 \%)$ indicating an increasing tendency towards the left colon ${ }^{30}$.

Highest occurrence of the tumor in male is between the age of $51-60$ years $(15.80 \%)$ and in female $31-40$ years $(10.40 \%)$. The gradual increase in frequency in male is from 21 to 60 years and then fall while in females highest frequency is in pre menopausal period i.e. child bearing age and then there is fall in the post menopausal period Typical distribution of Colorectal carcinoma in caecum and ascending colon is $15 \%$, hepatic flexure $02 \%$,transverse colon $05 \%$, splenic flexure $03 \%$, descending colon $10 \%$, remainder $65 \%$ arise in the sigmoid colon and rectum, of these $50 \%$ are in the rectum, $27 \%$ in the recto-sigmoid junction and remaining $14.95 \%$ in the sigmoid colon ${ }^{31}$. Carcinoma of colon is more common in females while carcinoma of rectum in males $^{32}$. Each year there are about 700,000 new cases and 400,000 deaths due to this disease world wide ${ }^{30}$
Multiple studies have been carried out to find out relation of these factors with colorectal carcinoma and most of these studies stress the decrease relationship of colorectal carcinoma with increased uptake of fiber diet $^{3,4,16,17,18,34}$ but this study shows that in this area mostly high roughage diet in the form of vegetable etc is used but even then there is increased occurrence of colorectal carcinoma. In females it is one to two decades earlier than the male indicating that some other etiological factors may also be involved. In one of the prospective study carried out at histopathology department of Chandka Medical College from January 1993 to December 1997 where 105 cases of colorectal carcinoma were studied, where $71(67.62 \%$ ) were male and $34(32.38 \%)$ were female with male to female ratio of 2.08: 1 where age pattern ranged from 12-75 years, average 44.63 years in males and 46.32 years in females .In this study $43.8 \%$ were below the age of 40 years but in our study is was $33.24 \%$ and occurrence of carcinoma was at higher age in female as compare to our study where $90(17.11 \%)$ females were below the age of 40 years ${ }^{35}$. In changing site distribution of colorectal carcinoma the \%age of right sided cancer was stable in males while increasing in females ${ }^{36}$ which is in comparison with our study. With the collaboration of Liquat Medical College and atomic energy medical center 125 cases of colorectal carcinoma were reviewed and it was found majority of the patients $76.00 \%$ belong to ruler areas where their may be indiscriminate exposure to pesticides or other factors and disease involved younger patients $45.6 \%$ bellow the age of 40 years $7,30,37,38$. At armed force institute of pathology in Rawalpindi during the period of one year (May 1990 to 1991), 78 cases of colorectal were diagnosed, age range was 16-84 years with male to female ratio of 1.6:1. 27 cases were below the age of 40 years, carcinoma of rectum was seen in $37(47.4 \%)$ cases followed by $9(11.5 \%)$ cases of caecum and sigmoid colon in $7(9.0 \%)^{39}$. Histologically $59(75.64 \%)$ were having well differentiated adenocarcinoma .A study of 40 cases of colorectal carcinoma at General Hospital PGMI Lahore in about one year showed $30(75 \%)$ adenocarcinoma $10(25 \%)$ mucinous adenocarcinoma ${ }^{40}$ with predominance of males $21(52.5 \%)$ and on left side $52.5 \%$. Male predominance was not only found in our study but in many other studies as well ${ }^{41,42,43}$. In our study commonest histological variety was adenocarcinoma, 
which is also evident in many other studies as well ${ }^{44,45,46,47,48,49}$. At district head quarter Rawalpindi where 60 cases of colorectal carcinoma were diagnosed during 1990. It was found that age range was $19-80$ years.The incidence of colorectal carcinoma less than 40 years was $18 \%$, commonest site was rectum $40 \%$ followed by sigmoid colon $30 \%{ }^{50}$. In a prospective study at Sheikh Zayed Hospital Lahore from January 1988 to December 1992 case evaluation of colorectal carcinoma was done, where it was found that cancer in lower $1 / 3$ of rectum was $60.7 \% 51$. In our population female usually undergo multiple pregnancies and constipation is the usual complaint during pregnancy which is due to lowering of gut muscle tone (progesterone effect) so they are more exposed to the so called carcinogens in the diet during pregnancy or there is probably deficiency of micronutrients as well such as Vit-A, C, E, A, carotene, calcium, and selenium and socio-economical status ,indiscriminate exposure of pesticide or others. All this data needs further evaluation of the increasing tendency of colorectal carcinoma and differences between child bearing age (15-49 years) and post-menopausal period in the females.

\section{CONCLUSION}

In our study the occurrence of colorectal carcinoma is southern Punjab is nearly in comparison with other western and local studies but in younger age group as compare to western studies particularly in females where it is one to two decade earlier than males which needs further work up and investigations.

\section{REFERENCES}

1. Taylor I. Colon polyp and colon cancer medicine international 1996, 2(9): 1063-1066.

2. Peter R. Havely; Polyp and carcinoma of large bowel, Medicine international 1982, 1(13-15): 626-629.

3. Vincent J, Davita Jr. Helman S, Steven AR. Cancer principles and practices of oncology $2^{\text {nd }}$ ed, 1985 Lippincot Philadelphia.

4. Vinary K, Ramzi S, Cartan S. Basic pathology 5th ed. W.B. Saunders, Philadelphia. 1992; 514-17.

5. Philip R, MCDONLAD S, QAZI R. Clinical oncology 7th ed
1993. W.B. Saunders, Philadelphia 576-77.

6. Ghafoor A, JaN MA and Bokhari H. Clinicl presentation and diagnosis of colorectal cancer.JCPSP 1998. MayJune; 11(4):547- 77

7. Mamoon N Ahmed M, Khan $\mathrm{AH}$ and Mushtaque S. Colorectal carcinoma in northern Pakistan. A clinicopathological study 1999 Nov . 11 (9) : 486-89.

8. Ahmad $M$, Khan $A H$, Mansoor A. The pattern of malignant tumours in Northern Pakistan Rawalpindi, AFPI 1990.

9. Jaffery NAD, Zaidi SHM. Cancer in Pakistan. J. Pak Med. Assoc 1987 ; 37: 178-83.

10. Grant N, Stemmerman, Abraharn MY. Cancer incidence following subtotal gastrectomy Japan Hawaii cancer study, Kuekini Med Centre Honbubs Hawaii. Gasteroenterology 1991; 101(3): 711-15.

11. Pollack ES, NomurA AMY, Hellburn LK. Prospective study of alcohol consumption and cancer. $N$ Engl J Med 1984; 310: 617-21.

12. Klatsky AL, Armstrong A, Friedman GD, Hiatt RA: The relation of alcoholic beverages use to colon and rectal cancer. Am J Epidemial 1988; 9: 875-84.

13. Maratha L, Slattery D, Linda M. Tobacco alcohol coffee and caffin as risk factor for colon cancer in low risk population.Epidemiology 1990; 1(2): 141-45.

14. Hecht SS, Hoffman D. Tobacco specific nitrosamines. An important group of carcinogens in tobacco and tobacco smoke. Carcinogenesis 1988; 9: 875-84.

15. Sharpe CR, SiemiatyckI JK, Rachet BP. The effects of smoking on the risk of colorectal carcinoma. Diseases of colon rectum. 2002 Aug; 45 ( 8) ;1041-1050.

16. Vincent J, Davita Jr. Helman S, Steven AR. Recent advances in oncology. Lippincot Philadelphia 1986;20929.

17. West DW, Slattery ML, Robinson LM. Dietry intake and colon cancer sex and anatomical sites, special effects. Am J Epidemial 1989; 130: 883-94.

18. Jensen OM. The epidemiological of large bowel cancer. In: Cohens LA (Editor). Diet nutrition and cancer: A critical evaluation Baco Raton CRC Press 1987; 27-45.

19. Ghandirian $\mathrm{P}$, Lacroix A, Maisonneuve P, Perret C, Potvin 
C, Gravel D, Bernad D, and Boyle P. Nutritional factors and colon carcinoma,a case control studyinvolving French Canadians in Monteral, Canada. cancer 1997 sep 1; 80(5):858-64.

20. Faiver J, Hedenne L, Morie. Epidemiological evidence for distinguishing. Gen Epi Comm Health 1989; 93: 35661.

21. Lynch HT, Gurigis H, Lynch J. Cancer of colon. Socioeconomic variables in community. Am J Epidemial 1975; 102: 119-27.

22. Osullivan MJ, McCarthy TV and Doyle CT. Familial Adenomatous Polyposis: From Bedside to benchside. Am J Clin Pathol 1998 May;109 (5): 521-26.

23. Silverbe RG E. Cancer statistics. Cancer 1985; 35: 1956 .

24. Hanock K, Moshe P, Hartiegs $S$. Is age an independent variable in the morbidity and mortality of patients with colorectal cancer. A prospective study. JCC 1991;34(4): 374-76.

25. Boyd J, Brdford B, Watane AL. Operative risk factor for colon reaction in the elderly. 743-46.

26. Ghafoor A, Jan NA, Bokhari H. Clinical presentation and diagnosis of colorectal cancer. J Coll Phys Surg Pak 1998; 8(3): 126-28.

27. Mehdi I, Frequency of gastrointestinal tumours at a teaching hospital in Karachi. J Pak Med Assoc 1998; 48(1): 14-17.

28. Al-Qasabi. Colorectal carcinoma: review of 110 cases. Ann Saudi Med 1990; 1(6): 646-49.

29. Ahmed M, Durani KM, Khawaja K. Colorectal cancer (a clinico-epidemiological study). Pak J Med Res 1990; 29(2): 62-65.

30. Talpur KA, Memon AS, Memon JM, Memon MA, Memon R. Management of colorectal cancer. J Surg Pak 2000; 5(4): 2-6.

31. David JB, AshleY. Histological appearance of tumours. 3rd ed 1980: 582-83.

32. Schrock TR. Cancer of colon and rectum . Current surgical diagnosis and treatment $4^{\text {th }}$ ed. Maruzen Asian Lang Medical Publication . Maruzen Asian (pt) Itd.1979,632-642.
33. McArdle CS. Colorectal cancer.Surgery internationa 1999, 44: 265-70.

34. Slattery ML, Sarenson AW, Mahoney AW. Diet and colon cancer assessment of risk by fibre diet and food sources. JNCL 1988; 1447-49.

35. Siyal AR, Shaikh SM, Baluch QD, Rathi SA, Chand H. A study of colorectal carcinoma. J Surg Pak 1999; 4(3): 14-16.

36. Tahada H, Ohsma T, Lwamoto S, Soshida R, Mahano M, Imada S. Changing site distribution of colorectal cancers in Japan. Dis Colon Rectum 2002; 45(9): 19992054.

37. Mehlo IA, Luqman MA, Khalilullah, Mallahi MA< RAsool MD. Colorectal carcinoma in Northern Pakistan: a retrospective study. Pak J Surg 1990; 6(2): 31-35.

38. Khawaja K, Chaudry $M A<$ Durani KM. Surgery to colorectal cancer. Proceeding of Sheikh Zayed Postgraduate Med 1990; 4: 4-7.

39. Mamoon N, Ahmad M, Khan AH, Mushtaq S. Colorectal carcinoma in Norhern Pakistan. Clinocopathological study. J Coll Phys Surg Pak 2001; 9(11): 486-89.

40. Ahmad MS, Sarfaraz R, Choudhry MR, Khan SA. A clinico-morphological study of colorectal carcinoma at Lahore General Hospital. Pak J Surg 19996; 12(4): 160-62.

41. Kenda JFN. Cancer of the large bowel in the African: a 15 year survey at Kinshasa University Hospital, Zaire. $\mathrm{Br}$ J Surg 1976; 63: 966-68.

42. McArdle CS, Hole D, Hansell D, Blumgart LH, Wood CB. Prospective study of colorectal cancer in the west of Scotland. 10 year follow up. Br J Surg 1990; 77: 280-82.

43. Khalid K, Durrani KM, Tufail M, Ahmad M, Colorectal cancer. A five year experience at Sheikh Zayed Hospital, Lahore. The Professional 1995; 2: 205-6.

44. Ahmad M, Durrani KM, Khawaja K. Colorectal cancer (A clinico-epidemiological study). Pak J Med Res 1990; 29: $62-65$

45. Ahmad J, Hashmi MA, Naveed IA, Hussain A, Amin D Spectrum of malignancies in Faisalabad 1986-90; Pak J Pathol 1992; 2 \& 3: 103-10.

46. Baloch NA. Surrent spectrum of intestinal obstruction. (Thesis). Lahore University of the Punjab 1991: 196. 
47. Kenda JFN. Cancer of the large bowel in the African: a 15 year survey at Kinshasa University Hospital Zaire. Br J Surg 1976; 63: 966-68.

48. Recalde M. Holyoke ED, Elias EG. Carcinoma of the colon, rectum and small canal in young patients. Surg Gynaecol Bostet 1974; 139: 909-13.

49. Okuno $M$, ljerara $T$, Ragayama $M$, Sakamoto $K$, Kato $Y$, Umeyam K. Colorectal carcinoma in young adults. Am
J Surg 1987; 154: 264-67.

50. Malik AZ, Latif S, Latif S, Nadeem A, Hussain M, Cheema K. Colorectal carcinoma: a Rawalpindi hospital experience. J Surg 1997; 138(14): 20-23.

51. Ahmad M, Durrani KM, Tufail M, Khalid K. Colorectal cancer. Five years experience at Sheikh Zayed Hospital, Lahore. Pak J Surg 1995; 11(4): 192-95. 